\title{
Article \\ Compassion and Workplace Incivility: Implications for Open Innovation
}

\author{
Sung-Hoon Ko ${ }^{1}$, Jongsung Kim ${ }^{2, *(1)}$ and Yongjun Choi ${ }^{3}$ \\ 1 Graduate School of Education, Kyonggi University, Suwon 16227, Korea; baumhoffnung@kyonggi.ac.kr \\ College of Liberal Arts and Interdisciplinary Studies, Kyonggi University, Suwon 16227, Korea \\ 3 College of Business Administration, Hongik University, Seoul 04066, Korea; yongjun.choi@hongik.ac.kr \\ * Correspondence: jongsungkim@kyonggi.ac.kr
}

check for updates

Citation: Ko, S.-H.; Kim, J.; Choi, Y. Compassion and Workplace Incivility: Implications for Open Innovation. J. Open Innov. Technol. Mark. Complex. 2021, 7, 95. https://doi.org/ 10.3390/joitmc7010095

Received: 3 February 2021

Accepted: 10 March 2021

Published: 15 March 2021

Publisher's Note: MDPI stays neutral with regard to jurisdictional claims in published maps and institutional affiliations.

Copyright: (c) 2021 by the authors. Licensee MDPI, Basel, Switzerland. This article is an open access article distributed under the terms and conditions of the Creative Commons Attribution (CC BY) license (https:/ / creativecommons.org/licenses/by/ $4.0 /)$.

\begin{abstract}
The purpose of this study was to examine mechanisms of how compassion experienced by employees affects workplace incivility. Specifically, this study aimed to explore the double mediation effect of positive emotion and leadership on the relationship between compassion and workplace incivility. Empirical results using survey data from 304 employees in South Korea confirm that employees who experience compassion at work are less likely to engage in workplace incivility. More importantly, positive emotions and positive leadership sequentially mediate the negative relationship between compassion and workplace incivility. The theoretical and practical implications are of this are also discussed.
\end{abstract}

Keywords: compassion; workplace incivility; positive emotion; positive leadership

\section{Introduction}

Business is a large part of open innovation in modern economies [1]. In particular, human capital within an organization plays an important role because its quality, including employees' knowledge, skills, abilities, and creativity, can increases an organization's ability to leverage innovation. However, it is inevitable that organizations will not be free from obstacles for such open innovation. One of the major obstacles is workplace incivility because this can have negative effects on employees' perceived support for innovation via hindering teamwork behaviors [2]. Furthermore, employees' experiences of incivility at work decreases their knowledge sharing [3] and innovative behaviors [4], which is detrimental for open innovation. Incivility, or rude and discourteous behavior, in the workplace is not simply a personal matter. Criminologists and psychologists, such as Laschinger and Read [5] have found that interpersonal assault begins with uncivil speech and minor abuse while, according to Anderson and Pearson [6], incivility is likely to lead to aggressive situations. In the workplace context, incivility can create conflict as well as high-intensity aggressive situations $[7,8]$, which, in turn, decrease employees organizational performance [9]. Thus, for open innovation, organizations need to prevent workplace incivility.

As employees' emotional exhaustion and stress increase as a result of incivility at work, researchers have explored several antecedents for its occurrence [10]. However, the actions that can be taken by organizations to mitigate workplace incivility still remain relatively unknown. This is surprising given that employees' behaviors are largely affected by their leaders and coworkers [11-14]. In addition, in the context of open innovation, previous studies have suggested that compassion at work is vital for innovative work behaviors, such as managerial idea generation [15], at both the individual and team level [16]. Hence, in an attempt to understand ways of decreasing workplace incivility, this study empirically investigated whether the experiences of compassionate behaviors at work reduced workplace incivility and, if so, what mechanisms could explain this phenomena. 
Previous studies have shown that leaders' as well as coworkers' uncivil behaviors reduce the frequency and quality of subordinates' positive behaviors at work, which, in turn, is detrimental for organizations [5,9,17-19]. Likewise, workplace incivility decreases an individual's job performance, job satisfaction [9], and psychological well-being [20], and increases employees' truancy or tardiness, which, in turn, negatively affects the organizational culture [21].

Leaders do not show uniform attitudes and behaviors towards employees. They provide different levels of emotional support which determine the type, as well as the amount of information that is exchanged between leaders and employees, which subsequently impacts the relationship quality [22]. Therefore, if employees and their leaders exchange compassion within the organization and form an empathetic culture to encourage positive leadership, their relationship will develop more positively, thus, reducing workplace incivility.

Hence, the aim of this study is to empirically investigate the effect of compassion (i.e., caring behaviors in response to the suffering of others) on workplace incivility in order to determine how to reduce workplace incivility. Specifically, by focusing on employees' affective reactions and their perceptions of positive leadership resulting from their experiences of compassionate behaviors at work, this study examines the mechanisms through which leaders' and coworkers' compassionate behaviors could reduce workplace incivility. The empirical results from this study will broaden our understanding of how insiders' behaviors, specifically with regard to compassion, could help to reduce workplace incivility. Specifically, given that studies such as those by Rhee, Hur, and Kim [23], and Woo and Kim [24], have provided somewhat limited empirical evidence of the link between compassion and workplace incivility, this present study contributes to the compassion literature by unboxing the unknown processes of how compassion could lessen employees' rudeness at work. In addition, whereas leadership researchers have empirically explored the link between many different types of leadership style [25-27], we still do not know how positive leadership affects incivility at work. Hence, this current study also provides contributions to the leadership literature. Furthermore, from a managerial point of view, this study provides organizations with recommendations to facilitate leaders' and coworkers' compassionate behaviors at work in order to facilitate open innovation within an organization, as well as to ensure the organization remains competitive in a dynamic business environment.

\section{Hypotheses Development}

\subsection{Compassion and Workplace Incivility}

Compassion experienced within an organization is defined as the interpersonal process of recognizing the suffering of others, experiencing emotional empathy for said suffering, and acting in a manner to relieve it $[28,29]$. Since the behavioral trait of compassion in the workplace involves the mental processes of organizational members who suffer disrespectful treatment in the workplace, it is most related to workplace incivility in the organization [28]. Compassion, which focuses on the suffering of others (i.e., paying attention to, feeling, and responding to the suffering of others), can be distinguished from sympathy, pity, or other emotions that arise within an organization [30,31]. For example, social support, which includes informational or emotional support, generally refers to a function that other people perform for an individual in a meaningful way [32]. While both compassion and social support in the workplace are considered coping resources, the concept of compassion focuses more specifically on the relationship with those who are suffering.

When employees experience compassion at work, they perceive others as personal rather than impersonal objects [33]. Thus, when leaders and coworkers express compassionate behaviors towards them, employees are likely to perceive that they are receiving genuine care from their leaders and coworkers, improving the quality of relationships between them, which demotivates them from engaging in uncivil behaviors. 
Hypothesis 1 (H1): Experiences of compassionate behaviors at work are negatively related to workplace incivility.

\subsection{Compassion and Positive Emotion}

Compassion at work is an individual's positive responses to the suffering of others within the organization [28]. It is crucial for organizations because it could result in many positive outcomes. For example, experienced compassion can serve as personal resources to increase one's self-regulation [34]. In addition, employees who experience compassion at work (i.e., who perceive they are genuinely cared about by others) are likely to form collective self-esteem, as well as a positive work-related identity, which, in turn, increases their job performance [35]. It can also lead to more constructive work behaviors, such as voice behaviors, because employees who experience compassion at work are likely to have high levels of affective commitment, which, in turn, facilitates constructive behaviors [36].

Experiences of compassion can evoke positive emotions in relationships with colleagues, subordinates, and superiors [31]. According to the affective events theory [37], employees recognize experiences of compassion at work (i.e., acts of temporal, mental, and physical care) as positive and meaningful work events, and thus, experience various positive emotions. Similarly, Lilius et al. [31] argued that employees who experience compassion are likely to feel positive emotions, such as pride, joy, inspiration, and comfort, because they perceive that they are being genuinely cared for by other organizational members. Empirical findings from previous research have supported this argument. For example, giving and receiving compassion in relationships among colleagues, subordinates, and superiors is related to positive emotions; compassion not only enhances positive emotions in organizational members but also has a positive effect on improving job performance $[4,28,35,38]$ because positive emotions energize productive performance by strengthening the emotional bond among employees. This is congruent with Bono and Ilies's [39] argument which states that helping employees experience positive emotions is one of the important psychological processes affecting individuals' productive outcomes. Therefore, drawing on past findings, we expect that employees who experience compassionate behaviors at work are more likely to experience positive emotions there.

Hypothesis 2 (H2): Experience of compassionate behaviors at work is positively related to positive emotions.

\subsection{Positive Emotion and Positive Leadership}

Cameron [40] argued that positive emotions formed by virtues and happiness energize positive attitudes. Specifically, in the context of this current study, we predict that employees who experience positive emotions triggered by their leaders' and coworkers' compassionate behaviors are likely to form positive attitudes toward their leaders and coworkers. It is well established in the field that employees' positive emotions facilitate positive attitudes and behaviors at work, such as engagement, creativity, collaboration, and performance including organizational citizenship behavior [41,42]. Similarly, leaders' positive emotions also energize their subordinates' positive behaviors, such as increasing their performance at work [43]. When employees experience positive emotions as a result of their leaders' and coworkers' compassionate behaviors, they are likely to perceive congruence between their leaders' and coworkers' positive attitudes towards each other and themselves. Affective congruence between an employee and his or her leaders and coworkers is likely to increase the relationship quality between them, resulting in more favorable appraisal of their leaders because symbolic meanings in social exchanges are partly determined by emotional exchanges between the two [44]. Specifically, this is because leaders' and coworkers' compassionate behaviors serve as a means to evoke employees' positive emotions, which, in turn, increase quality relationships, and employees will perceive that their leaders exhibit positive leadership at work. 
Hypothesis 3 (H3): Employees' positive emotions are positively related to their perceptions of their leaders' positive leadership.

\subsection{Positive Leadership and Workplace Incivility}

In a study conducted on residents in U.S. mid-western cities, Tepper [18] showed that superiors' uncivil behaviors in the workplace not only lowered subordinates' organizational commitment but also negatively affected their job and life satisfaction; this is consistent with a study result that showed that uncivil behaviors increase psychological suffering, which could influence turnover. Schilling [45] also argued that superiors' uncivil leadership behaviors interfere with subordinates' motivation, organizational commitment, and voluntary innovation activities, leading to poor performance.

Meanwhile, positive leadership forms positive relationships with organizational members by understanding their differences [46]. Positive relationships raise the levels of vitality, learning, collaboration, resource utilization, cost and time savings, and human resource development in the organization [47]. Furthermore, positive leadership has a positive effect on productivity because it improves the personal relationship between superiors and subordinates, increases organizational commitment [48], and reduces workplace incivility [46]. Positive communications occur when positive and mutually supportive expressions are used in the organization [40]. Superiors and subordinates who experience positive leadership will have positive communications and eventually avoid uncivil behaviors.

\section{Hypothesis 4 (H4): Positive leadership is negatively related to workplace incivility.}

\subsection{Double Mediation Effect of Positive Emotion and Positive Leadership}

Employees who experience compassion as an act of temporal, mental, and physical caring within the organization, form positive emotions [49]. Organization members who have developed positive emotions through compassion in response to suffering positively recognize the leadership shown by their superior or team leader; that is, employees perceive the leadership of their team leader as positive, a leadership that encourages members and helps them emotionally [40,50]. By creating positive emotions through compassion, both team leaders who show positive leadership and members who experience it present a highquality connection and reduced workplace incivility [49]. Since leaders and employees who have experienced compassion recognize each other as personal subjects for care and encouragement, rather than material objects for performance, positive leadership will eventually reduce workplace incivility. Hence, building upon the previous hypotheses, we predict the following:

Hypothesis 5 (H5): Positive emotion and positive leadership sequentially mediate the relationship between compassion and workplace incivility.

\section{Methods}

\subsection{Study Participants and Procedure}

This study employed a survey method to collect data from employees working at 15 corporations located in the metropolitan areas in South Korea. A total of 320 employees responded to the survey; after excluding 16 surveys with insincere responses, 304 surveys were used to test the hypotheses.

The final sample consisted of 129 men (42.4\%) and 175 women (57.6\%). By age, 54 respondents were in their 20s (17.8\%), 125 in their 30s (41.1\%), 90 in their 40s $(29.6 \%)$, and 35 in their $50 \mathrm{~s}(11.5 \%)$. By position within the organization, 112 represented general staff $(36.8 \%)$, 91 were assistant managers $(29.9 \%), 60$ were team managers $(19.7 \%)$, and $41(13.5 \%)$ were assistant directors or higher. By work experience, $132(43.4 \%)$ marked $1-4$ years, $80(26.3 \%)$ 5-9 years, $56(18.4 \%)$ 10-14 years, 20 (6.6\%) $15-19$ years, and $16(5.3 \%)$

20 or more years. 


\subsection{Measures}

\subsubsection{Compassion}

Three items developed by Lilius et al. [31] were used to measure the construct of compassion: "I often experience compassion at my workplace", "I often experience compassion from my supervisor", and "I often experience compassion from my colleagues", rated on a 5-point Likert scale. The correlation among the items was sufficiently strong (Cronbach's $\alpha=0.894$ ), confirming the reliability of the measure of compassion.

\subsubsection{Positive Emotion}

Positive emotion, here, refers to a positive emotional state experienced by individuals within their organization. Four measurement items used by Lilius et al. [31] were adopted to gauge the construct of positive emotion in this study, including "I am proud of all my work" and "I am happy with all my work". The items were rated on a 5-point Likert scale, and the reliability of the measure of positive emotion was excellent (Cronbach's $\alpha=0.916$ ).

\subsubsection{Positive Leadership}

In this study, positive leadership was operationally defined as a "leadership that induces positive emotions and a positive organizational culture while interacting with all team members". Fourteen measurement items in the positive leadership questionnaire (PLQ) used in Cameron's study [40] were modified to suit the domestic situation and this study. Examples of items include: "Our team leader allows team members to share personal information so that they can know and care about the difficulties team members have"; "our team leader has a lot of positive energy and encourages team members to have such energy", and so on. The construct of positive leadership was measured on a 5-point Likert scale, and the reliability coefficient of the items was excellent (Cronbach's $\alpha=0.963$ ).

\subsubsection{Workplace Incivility}

Workplace incivility within an organization can be defined as a "low-intensity deviant behavior with ambiguous intent to harm the target, in violation of workplace norms for mutual respect" [6]. Seven scales developed by Cortina et al. [9] were translated and used for this study. Examples of questions include: "My superiors or coworkers make demeaning or derogatory remarks about me"; "my superiors or coworkers doubt my judgment in my job", and so on. A 5-point Likert scale was used to measure the items, and the reliability coefficient for the construct of positive leadership was also excellent (Cronbach's $\alpha=0.942$ ).

\subsubsection{Control Variables}

This study entered demographic variables (gender, age, position, career experience, tenure) into the analytic model to control their possible influence on compassion, positive emotion, positive leadership, and workplace incivility. Furthermore, potentially confounding effects of the personality traits on the major variables in this study were controlled. This study employed a survey method to collect data from employees working at 15 corporations located in the metropolitan area in South Korea. A total of 320 employees responded to the survey; after excluding 16 surveys with insincere responses, 304 surveys were used to test the hypotheses.

\subsection{Common Method Bias}

This study collected data on both independent and dependent variables from the same respondents simultaneously, raising an issue about a potential common method bias. Hence, the study conducted a Harmon single factor test [51,52] as an ex-post remedy to see if the measurement involves a common method bias issue. Podsakoff et al. [51] classified the causes of common method bias into four categories; Harmon's single factor test is considered to be useful to detect the bias since it uses exploratory factor analysis. Six factors with an eigenvalue greater than 1 were detected; the covariance explained by the 
first factor was estimated at $11 \%$, indicating that the common method bias is not a serious concern (i.e., not a likely contaminant of the measurement).

\subsection{Common Method Bias}

This study employed structural equation modeling for data analysis using AMOS 24.0. A confirmatory factor analysis was conducted to test the measurement model with four latent variables and 28 indicators (three indicators to measure the construct of compassion; four indicators for positive emotion; 14 for positive leadership; seven for workplace incivility). Then, we examined the correlation coefficients and average variance extracted (AVE) to check for multicollinearity and discriminant validity, and Cronbach's $\alpha$ and factor loadings to check the convergent reliability.

\section{Results}

\subsection{Confirmatory Factor Analysis}

The goodness-of-fit test results from the confirmatory factor analysis were: $\chi^{2}=656.667$ $(\mathrm{df}=339, p=0.000), \mathrm{CFI}=0.959, \mathrm{TLI}=0.954, \mathrm{GFI}=0.866, \mathrm{NFI}=0.918, \mathrm{RMSEA}=0.055$, and $\mathrm{RMR}=0.044$. All modeling fit indices were greater than a traditional threshold, demonstrating that the measurement items for the latent variables employed in the research mode satisfied the conventional criteria.

\subsection{Hypotheses Testing}

Table 1 shows the Pearson correlation coefficients of the latent variables modeled in this study. The correlation coefficients were between 0.135 and $0.575(p<0.01)$, indicating that multicollinearity was not a serious issue in this study. Furthermore, the AVEs were all greater than 0.6 , a traditionally acceptable threshold, confirming the discriminant validity. Meanwhile, Cronbach's $\alpha$, the composite reliability coefficient, and factor loadings for each construct were all greater than 0.7 , confirming the convergent validity of the constructs employed in the research model.

Table 1. Descriptive statistics.

\begin{tabular}{|c|c|c|c|c|c|c|}
\hline Variable & Mean & SD & 1 & 2 & 3 & 4 \\
\hline 1. Compassion & 3.433 & 0.706 & 0.723 & & & \\
\hline 2. Positive Emotion & 3.229 & 0.707 & $0.356^{* *}$ & 0.761 & & \\
\hline 3. Positive Leadership & 3.033 & 0.789 & $0.481^{* *}$ & $0.575^{* *}$ & 0.771 & \\
\hline 4. Workplace Incivility & 2.57 & 0.9 & $-0.169^{* *}$ & $-0.135^{* *}$ & $-0.296^{* *}$ & 0.752 \\
\hline
\end{tabular}

Note. ${ }^{* *} p<0.01$; the italic number in the diagonal is the square root of the average variance extracted (AVE).

Table 2 presents the path coefficients and statistical significance. The results are as follows: Compassion was negatively and significantly associated with workplace incivility $(\beta=-0.236, C R=-3.694, p<0.001)$, confirming Hypothesis 1 . Compassion was positively and significantly associated with positive emotion $(\beta=0.356, \mathrm{CR}=6.709, p<0.001)$, supporting Hypothesis 2, as expected. Positive emotion was also positively and significantly associated with positive leadership $(\beta=0.642, C R=12.409, p<0.001)$, confirming Hypothesis 3, as expected. Meanwhile, positive leadership was negatively and significantly related to workplace incivility $(\beta=-0.319, \mathrm{CR}=-5.051, p<0.001)$, supporting Hypothesis 4 , as predicted. 
Table 2. Path analysis results.

\begin{tabular}{cccccc}
\hline & Path & b & SE & CR & $p$ \\
\hline H1 & $\begin{array}{c}\text { Compassion } \rightarrow \\
\text { Workplace Incivility } \\
\text { Compassion } \rightarrow\end{array}$ & -0.263 & 0.071 & -3.694 & $p<0.001$ \\
H2 & $\begin{array}{c}\text { Positive Emotion } \\
\text { Positive Emotion } \rightarrow\end{array}$ & 0.356 & 0.053 & 6.709 & $p<0.001$ \\
H3 & $\begin{array}{c}\text { Positive Leadership } \\
\text { Positive Leadership } \rightarrow \\
\text { Workplace Incivility }\end{array}$ & -0.642 & 0.052 & 12.409 & $p<0.001$ \\
\hline
\end{tabular}

This study used bootstrap sampling to test the significance of mediating effects in an effort to overcome the limitations of the conventional approach [53,54]. As shown in Table 3, the bootstrap estimate of the indirect effect between compassion and workplace incivility was significant (LLCI95\% $=-0.1163$, ULC195\% $=-0.0254$ ), supporting Hypothesis 5; that the relationship between compassion and workplace incivility is sequentially mediated by positive emotion and positive leadership.

Table 3. Indirect effects for the double mediation.

\begin{tabular}{ccccc}
\hline & Effect & LLCI95\% & ULCI95\% & BootSE \\
\hline Total indirect effect & -0.1637 & -0.2663 & -0.0681 & 0.0501 \\
Compassion $\rightarrow$ PE $\rightarrow$ Workplace Incivility & 0.0276 & -0.04 & 0.1003 & 0.0355 \\
Compassion $\rightarrow$ PL $\rightarrow$ Workplace Incivility & -0.1245 & -0.2081 & -0.0523 & 0.04 \\
Compassion $\rightarrow$ PE $\rightarrow$ PL & -0.0668 & -0.1187 & -0.0262 & 0.0236 \\
$\rightarrow$ Workplace Incivility & & & & \\
\hline
\end{tabular}

Note: $\mathrm{PE}=$ positive emotion; $\mathrm{PL}$ = positive leadership.

\section{Discussion: Positive Emotion, Positive Leadership, Workplace Incivility, and Open Innovation}

This study empirically examined the relationship of compassion with workplace incivility and the role of positive emotion and positive leadership in mediating the relationship. The study found that compassion and positive leadership were both significant factors that reduced workplace incivility, and that compassion was negatively and significantly related to workplace incivility through positive emotion and positive leadership. Therefore, this study concludes that compassion, an act of temporal, mental, and physical caring for the suffering of other members in an organization, generates positive emotions in members; hence positive emotions contribute to forming positive leadership, which eventually decreases workplace incivility. The next sections provide a discussion and the theoretical implications of this present study.

\subsection{Discussion: Positive Emotion, Positive Leadership, and Workplace Incivility}

First, the study empirically verified the causal relationship of compassion on other outcome variables. This study is particularly meaningful since the causal relationship between compassion and workplace incivility has not been sufficiently studied in the field of business administration and organizational behavior. Thus, our findings add valuable empirical evidence for the effect of compassion on workplace incivility, providing fruitful ways to further explore potential moderators and mediators.

Second, this study empirically examined the causal relationships among compassion, positive emotion, positive leadership, and workplace incivility; for this reason, it is differentiated from previous studies that have dealt with the causal relationship between compassion and other positive variables. Previous studies have explored the roles of several positive psychological constructs as mediators to explain the effects of compassion at work. For example, Lilius [31] empirically showed the mediation effect of positive emotion on the relationship between compassion and emotional commitment. Similarly, 
Moon et al. [38] demonstrated that positive work-related identity can explain the positive link between compassion and organizational citizenship behavior. Unlike the previous findings, this present study empirically verified the double mediation effect of positive emotion and positive leadership on the relationship between compassion and workplace incivility, providing a theoretical contribution to the future research on compassion at work.

In addition, previous studies exploring the roles of compassion in the context of workplace incivility either investigated its moderating role in the relationship between incivility and job performance [23] or in a very specific organizational setting, such as the field of nursing [24]. Thus, our study's findings add valuable knowledge of the mechanisms through how compassion affect workplace incivility by quantitatively examining the untapped mediators (i.e., positive emotion and positive leadership) using data from employees in more general office settings.

\subsection{Discussion: Positive Emotion, Positive Leadership, and Open Innovation}

First, our results provide empirical evidence showing that, to lessen workplace incivility, which is one of the major obstacles for open innovation, having employees experience compassion is vital. Unlike most previous studies that focused on the positive effects of workplace compassion on the creation of the culture for open innovation [15,16], by taking a somewhat different approach for the open innovation culture, this current study demonstrated the roles of compassion in tackling certain barriers to open innovation culture in organizations. More specifically, by focusing on workplace incivility, which is well-known to hinder teamwork behavior [2] as well as knowledge sharing behaviors [3], the current study adds insights to the open innovation literature by exploring the roles of compassion from the lens of open innovation.

Secondly, the empirical evidence of the link between positive leadership and workplace incivility is somewhat limited [50]. Specifically, the previous literature on leadership, which examined its effects on workplace incivility, focused on many different forms or styles of leadership, such as passive leadership [25], transformational leadership [26], authentic leadership [5,27], but not positive leadership. Thus, our results showing the negative effect of positive leadership on workplace rudeness (i.e., workplace incivility) provide a theoretical contribution to the field of leadership.

Furthermore, in the context of open innovation, previous studies emphasized that, in order to facilitate employee innovative behaviors, appropriate leadership styles need to be carried out [55,56]. For example, Ahmed Iqbal, Abid, Contreras, Hassan, and Zafar [57] showed that ethical leadership could lead to employee innovative work behaviors because it helps to create an open innovation culture that is favorable for innovative work behaviors. Given that positive leadership is conducive to creativity, which is vital for innovation processes [58], our results provide contributions to the open innovation literature, by showing how to promote positive leadership at work. That is, because positive leadership could facilitate employee innovative behavior, our results highlight that having them experience compassion at work could serve as means to develop and even demonstrate one's positive leadership.

\section{Conclusions}

\subsection{Implications}

Compassion is important not only for one's psychological well-being, but also for encouraging innovative behaviors at work $[4,16]$. Given that workplace incivility is one of the major hindrances for open innovation [2], the results from this current study provide practical insight for organizations about how to mitigate such an obstacle. Specifically, this study found that compassion is a factor that plays an essential role in reducing workplace incivility within organizations. This finding suggests the practical implication that forming an empathic organizational culture within the organization could be an effective way to reduce workplace incivility among superiors, subordinates, and colleagues, ultimately contributing to developing a positive organizational culture. That is, the results imply that 
uncivil behaviors occurring in the organization between superiors and subordinates could decrease by helping them express and experience compassionate behavior at work. More in general, the results of this study suggest that compassion as an act of caring for other members' suffering contributes to a reduction in uncivil behaviors in the organization by enabling personal and in-depth relationships between superiors and subordinates to be formed. Compassion is an emotion that involves recognizing, feeling, and responding to the suffering of others; hence, organizational members who experience compassion will develop respect toward other persons which, in turn, facilitates open innovation within organizations. Furthermore, such favorable work environments that create emotional attachment among employees will be beneficial for energizing open innovation [59,60], which is essential for organizations to gain competitive advantages and pursue long-term sustainability [61].

\subsection{Limitations and Future Research}

Despite the theoretical and practical implications, this study has the following limitations that warrant future research. First, the generalizability of the findings in this study may be limited (i.e., potentially limited external validity). The sample data used to test the hypotheses in this study were collected only from employees working at certain corporations in one specific area. Furthermore, the distribution of respondents was somewhat skewed in terms of employment type, company size, and education level; that is, they were mostly regular employees and highly educated (i.e., college and university graduates). It is significant that previous studies have noted that the incidence of workplace incivility within the organization was higher for women or irregular employees [9]. Future research needs to be conducted with a more representative sample in terms of the respondents demographics, including age, area, and position/title. Furthermore, future research is warranted to examine workplace incivility differences in the organization by gender and employment type.

Second, the scale to measure the construct of compassion in this study may need improvement. The measurement items for compassion were developed by Lilius et al. [31] to examine its causal relationship with positive variables, while this study focuses on examining the double mediation effect of positive emotion and positive leadership. Future research needs to employ a qualitative or mixed-methods approach based on the grounded theory to unveil more valid measurement items to reflect different research contexts.

Third, this study's research model includes workplace incivility as an outcome variable to empirically examine how it is affected by compassion through positive emotion and positive leadership. Future research needs to consider including more outcome variables (e.g., job performance, organizational citizenship behavior, organizational identification, and so on) to examine the causal relationships of compassion with them.

Fourth, this study collected data on both independent and dependent variables from the same respondents simultaneously, raising an issue about a potential common method bias. As per operational definitions of the study variables, such as compassion, positive emotion, positive leadership, and experienced workplace incivility, the use of self-reports was inevitable. It is noteworthy that self-reports do not always inflate the bias [62]. This present study conducted a Harmon single factor test [51,52] as an ex-post remedy to see if the measurement involves a common method bias issue. However, because all the variables were collected at one-time wave, we acknowledge that, although we conducted the Harmon single factor test [51,52], we cannot completely rule out the possibility of common method bias. Thus, in addition to the Harmon single factor test, future research can benefit by using longitudinal research design.

Finally, the generalizability of this study's findings is limited because the sample includes only Korean employees. For example, a growing body of empirical studies suggest that cultural values may affect how incivility plays out at work. For example, Welbourne, Gangadharan, and Sariol [63] showed that employees with different ethnicities and cultural values are likely to have different levels of vulnerability as well as different 
reactions (e.g., job satisfaction) to workplace incivility. Likewise, comparing Korean to Spanish individuals, Moon and Sánchez-Rodríguez [64] showed that normative reactions to incivility can be different in relation to cultural values, such as power distance. Therefore, future research should be conducted with samples from various countries to compare the results between countries and create more generalizable findings.

Author Contributions: S.-H.K. wrote the first draft of this manuscript and designed the model used in the study. S.-H.K. and J.K. designed the methodology section, and conducted and analyzed the empirical test results. Y.C. supplemented several parts of the paper and refined the entire article. S.-H.K. and J.K. interpreted the theoretical and practical implications of our findings. All authors contributed to writing this manuscript. All authors have read and agreed to the published version of the manuscript.

Funding: This work was supported by the National Research Foundation of Korea Grant funded by the Korean Government (NRF-2017S1A6A4A01019059).

Conflicts of Interest: The authors declare no conflict of interest.

\section{References}

1. Yun, J.J.; Won, D.; Park, K. Entrepreneurial cyclical dynamics of open innovation. J. Evol. Econ. 2018, 28, 1151-1174. [CrossRef]

2. Yang, J. Thriving organizational sustainability through innovation: Incivility climate and teamwork. Sustainability $2016,8,860$. [CrossRef]

3. Farrukh, M.; Ting, H.; Shahzad, I.A.; Hua, Z. Can incivility impede knowledge sharing behaviour? Int. J. Inf. Syst. Chang. Manag. 2018, 10, 295-310.

4. Hur, W.-M.; Moon, T.; Jun, J.-K. The effect of workplace incivility on service employee creativity: The mediating role of emotional exhaustion and intrinsic motivation. J. Serv. Mark. 2016, 30, 302-315. [CrossRef]

5. Laschinger, H.K.S.; Read, E.A. The effect of authentic leadership, person-job fit, and civility norms on new graduate nurses' experiences of coworker incivility and burnout. J. Nurs. Adm. 2016, 46, 574-580. [CrossRef] [PubMed]

6. Andersson, L.M.; Pearson, C.M. Tit for tat? The spiraling effect of incivility in the workplace. Acad. Manag. Rev. 1999, $24,452-471$. [CrossRef]

7. Felblinger, D.M. Incivility and bullying in the workplace and nurses' shame responses. J. Obstet. Gynecol. Neonat. Nurs. 2008, 37, 234-242. [CrossRef]

8. Felblinger, D.M. Bullying, incivility, and disruptive behaviors in the healthcare setting: Identification, impact, and intervention. Front. Health Serv. Manag. 2009, 25, 13-23. [CrossRef]

9. Cortina, L.M.; Magley, V.J.; Williams, J.H.; Langhout, R.D. Incivility in the workplace: Incidence and impact. J. Occup. Health Psychol. 2001, 6, 64-80. [CrossRef] [PubMed]

10. Schilpzand, P.; De Pater, I.E.; Erez, A. Workplace incivility: A review of the literature and agenda for future research. J. Org. Behav. 2016, 37, S57-S88. [CrossRef]

11. Bonner, J.M.; Greenbaum, R.L.; Mayer, D.M. My boss is morally disengaged: The role of ethical leadership in explaining the interactive effect of supervisor and employee moral disengagement on employee behaviors. J. Bus. Ethics 2016, 137, 731-742. [CrossRef]

12. Chiaburu, D.S.; Harrison, D.A. Do peers make the place? Conceptual synthesis and meta-analysis of coworker effects on perceptions, attitudes, OCBs, and performance. J. Appl. Psychol. 2008, 93, 1082-1103. [CrossRef]

13. Eisenberger, R.; Stinglhamber, F.; Vandenberghe, C.; Sucharski, I.L.; Rhoades, L. Perceived supervisor support: Contributions to perceived organizational support and employee retention. J. Appl. Psychol. 2002, 87, 565-573. [CrossRef]

14. Sguera, F.; Bagozzi, R.P.; Huy, Q.N.; Boss, R.W.; Boss, D.S. The more you care, the worthier I feel, the better I behave: How and when supervisor support influences (un)ethical employee behavior. J. Bus. Ethics 2018, 153, 615-628. [CrossRef]

15. Brink, T. Passion and compassion represent dualities for growth. Int. J. Organ. Anal. 2015, 23, 41-60. [CrossRef]

16. Lefebvre, J.I.; Montani, F.; Courcy, F.; Dagenais-Desmarais, V. Self-compassion at work: A key for enhancing well-being and innovation through social safeness at multiple levels. Can. J. Adm. Sci. 2020. [CrossRef]

17. Mitchell, M.S.; Ambrose, A.L. Abusive supervision and workplace deviance and the moderating effects of negative reciprocity beliefs. J. Appl. Psychol. 2007, 92, 1159-1168. [CrossRef]

18. Tepper, B.J. Consequences of abusive supervision. Acad. Manag. J. 2000, 43, 178-190.

19. Thau, S.; Mitchell, M.M. Self-gain or self-regulation impairment? Tests of competing explanations of the supervisor abuse and employee deviance relationship through perceptions of distributive justice. J. Appl. Psychol. 2010, 95, 1009-1031. [CrossRef] [PubMed]

20. Lim, S.; Cortina, L.M.; Magley, V.J. Personal and workgroup incivility: Impact on work and health outcomes. J. Appl. Psychol. 2008, 93, 95-107. [CrossRef]

21. Lim, S.; Cortina, L.M. Interpersonal mistreatment in the workplace: The interface and impact of general incivility and sexual harassment. J. Appl. Psychol. 2005, 90, 483-496. [CrossRef] 
22. Graen, G.B.; Uhl-Bien, M. Relationship-based approach to leadership: Development of leader-member exchange (LMX) theory of leadership over 25 years: Applying a multi-level multi-domain perspective. Leadersh. Q. 1995, 6, 219-247. [CrossRef]

23. Rhee, S.-Y.; Hur, W.-M.; Kim, M. the relationship of coworker incivility to job performance and the moderating role of self-efficacy and compassion at work: The job demands-resources (JD-R) approach. J. Bus. Psychol. 2017, 32, 711-726. [CrossRef]

24. Woo, C.H.; Kim, C. Impact of workplace incivility on compassion competence of Korean nurses: Moderating effect of psychological capital. J. Nurs. Manag. 2020, 28, 682-689. [CrossRef] [PubMed]

25. Harold, C.M.; Holtz, B.C. The effects of passive leadership on workplace incivility. J. Organ. Behav. 2015, 36, 16-38. [CrossRef]

26. Bureau, J.S.; Gagné, M.; Morin, A.J.; Mageau, G.A. Transformational leadership and incivility: A multilevel and longitudinal test. J. Interpers. Violence 2021, 36, NP448-NP473. [CrossRef] [PubMed]

27. Alkaabi, O.; Wong, C. Relationships among authentic leadership, manager incivility and trust in the manager. Leadersh. Health Serv. 2020, 33, 27-42. [CrossRef]

28. Dutton, J.E.; Frost, P.J.; Worline, M.C.; Lilius, J.M.; Kanov, J.M. Leading in times of trauma. Harv. Bus. Rev. 2002, 80, 54-61.

29. Frost, P.J.; Dutton, J.E.; Worline, M.C.; Wilson, A. Narratives of compassion in organizations. Emot. Organ. 2000, 2, $25-45$.

30. Dutton, J.E.; Workman, K.M.; Hardin, A.E. Compassion at work. Annu. Rev. Organ. Psychol. Organ. Behav. 2014, 1, 277-304. [CrossRef]

31. Lilius, J.M.; Worline, M.C.; Maitlis, S.; Kanov, J.; Dutton, J.E.; Frost, P. The contours and consequences of compassion at work. J. Organ. Behav. Int. J. Ind. 2008, 29, 193-218. [CrossRef]

32. Thoits, P.A. Stress, coping, and social support processes: Where are we? What next? J. Health Soc. Behav. 1995, 35, 53-79. [CrossRef]

33. Frost, P. Toxic Emotions at Work-How Compassionate Managers Handle Pain and Conflicts; Harvard Business School: Boston, MA, USA, 2003.

34. Choi, H.J.; Lee, S.; No, S.R.; Kim, E.I. Effects of compassion on employees' self-regulation. Soc. Behav. Personal. Int. J. 2016, 44, 1173-1190. [CrossRef]

35. Ko, S.H.; Choi, Y. Compassion and job performance: Dual-paths through positive work-related identity, collective self-esteem, and positive psychological capital. Sustainability 2019, 11, 6766. [CrossRef]

36. Nisar, A.; Abid, G.; Elahi, N.S.; Ahsan Athar, M.; Farooqi, S. Impact of compassion on voice behavior: A moderated mediation model. J. Open Innov. Technol. Mark. Complex. 2020, 6, 148. [CrossRef]

37. Weiss, H.M.; Cropanzano, R. Affective events theory: A theoretical discussion of the structure, causes and consequences of affective experiences at work. In Research in Organizational Behavior: An Annual Series of Analytical Essays and Critical Reviews Vol. 18; Staw, B.M., Cummings, L.L., Eds.; Elsevier Science/JAI Press: Greenwich, CT, USA, 1996; pp. 1-74.

38. Moon, T.W.; Hur, W.M.; Ko, S.H.; Kim, J.W.; Yoo, D.K. Positive work-related identity as a mediator of the relationship between compassion at work and employee outcomes. Hum. Factors Ergon. Manuf. Serv. Ind. 2016, 26, 84-94. [CrossRef]

39. Bono, J.E.; Ilies, R. Charisma, positive emotions and mood contagion. Leadersh. Q. 2006, 17, 317-334. [CrossRef]

40. Cameron, K. Positive Leadership: Strategies for Extraordinary Performance; Berrett-Koehler Publishers: San Francisco, CA, USA, 2012.

41. Avey, J.B.; Wernsing, T.S.; Luthans, F. Can positive employees help positive organizational change? Impact of psychological capital and emotions on relevant attitudes and behaviors. J. Appl. Behav. Sci. 2008, 44, 48-70. [CrossRef]

42. Diener, E.; Thapa, S.; Tay, L. Positive emotions at work. Annu. Rev. Organ. Psychol. Organ. Behav. 2020, 7, 451-477. [CrossRef]

43. McColl-Kennedy, J.R.; Anderson, R.D. Impact of leadership style and emotions on subordinate performance. Leadersh. Q. 2002, 13, 545-559. [CrossRef]

44. Newcombe, M.J.; Ashkanasy, N.M. The role of affect and affective congruence in perceptions of leaders: An experimental study. Leadersh. Q. 2002, 13, 601-614. [CrossRef]

45. Schilling, J. From ineffectiveness to destruction: A qualitative study on the meaning of negative leadership. Leadership 2009, 5, 102-128. [CrossRef]

46. Clifton, D.O.; Harter, J.K. Investing in Strengths. In Positive Organizational Scholarship: Foundations of a New Discipline; Cameron, K.S., Dutton, J.E., Quinn, R.E., Eds.; Berrett-Koeller: San Francisco, CA, USA, 2003; pp. 111-121.

47. Kahn, W.A. Meaningful Connections: Positive Relationships and Attachments at Work. In LEA's Organization and Management Series. Exploring Positive Telationships at Work: Building a Theoretical and Research Foundation; Dutton, J.E., Ragins, B.R., Eds.; Lawrence Erlbaum Associates Publishers: Mahwah, NJ, USA, 2007; pp. 189-206.

48. Condon, P.; Feldman Barrett, L. Conceptualizing and experiencing compassion. Emotion 2013, 13, 817-821. [CrossRef] [PubMed]

49. Avolio, B.J.; Gardner, W.L. Authentic leadership development: Getting to the root of positive forms of leadership. Leadersh. Q. 2005, 16, 315-338. [CrossRef]

50. Walsh, B.M.; Lee, J.J.; Jensen, J.M.; McGonagle, A.K.; Samnani, A.K. Positive leader behaviors and workplace incivility: The mediating role of perceived norms for respect. J. Bus. Psychol. 2018, 33, 495-508. [CrossRef]

51. Podsakoff, P.M.; MacKenzie, S.B.; Lee, J.-Y.; Podsakoff, N.P. Common method biases in behavioral research: A critical review of the literature and recommended remedies. J. Appl. Psychol. 2003, 88, 879-903. [CrossRef]

52. Podsakoff, P.M.; Organ, D.W. Self-reports in organizational research: Problems and prospects. J. Manag. 1986, 12, 531-544. [CrossRef]

53. Preacher, K.J.; Hayes, A.F. SPSS and SAS procedures for estimating indirect effects in simple mediation models. Behav. Res. Methods Instrum. Comput. 2004, 36, 717-731. [CrossRef] [PubMed] 
54. Preacher, K.J.; Hayes, A.F. Asymptotic and resampling strategies for assessing and comparing indirect effects in multiple mediator models. Behav. Res. Methods 2008, 40, 879-891. [CrossRef]

55. Abdolmaleki, J.; Ashloublagh, M.; Shahrabi, M.; Ashlaghi, A.; Safdari, S. A study on effects of leadership style on innovation: A case study from automaker industry. Manag. Sci. Lett. 2013, 3, 1977-1982. [CrossRef]

56. Agbim, K.C. The impact of organizational structure and leadership styles on innovation. IOSR J. Bus. Manag. 2013, 6, 56-63. [CrossRef]

57. Ahmed Iqbal, Z.; Abid, G.; Contreras, F.; Hassan, Q.; Zafar, R. Ethical Leadership and Innovative Work Behavior: The Mediating Role of Individual Attributes. J. Open Innov. Technol. Mark. Complex. 2020, 6, 68. [CrossRef]

58. Burgelman, R.A.; Kosnik, T.J.; Van den Poel, M. toward an innovative capabilities audit framework. In Strategic Management of Technology and Innovation; Burgelman, R.A., Maidique, M.A., Eds.; Irwin: Homewood, IL, USA, 1988; pp. 31-44.

59. Yun, J.J.; Zhao, X.; Wu, J.; Yi, J.C.; Park, K.; Jung, W. business model, open innovation, and sustainability in car sharing industry-Comparing three economies. Sustainability 2020, 12, 1883. [CrossRef]

60. Van de Vrande, V.; De Jong, J.P.; Vanhaverbeke, W.; De Rochemont, M. Open innovation in SMEs: Trends, motives and management challenges. Technovation 2009, 29, 423-437. [CrossRef]

61. Yun, J.J.; Liu, Z. Micro- and macro-dynamics of open innovation with a Quadruple-Helix Model. Sustainability 2019, $11,3301$. [CrossRef]

62. Conway, J.M.; Lance, C.E. What reviewers should expect from authors regarding common method bias in organizational research. J. Bus. Psychol. 2010, 25, 325-334. [CrossRef]

63. Welbourne, J.L.; Gangadharan, A.; Sariol, A.M. Ethnicity and cultural values as predictors of the occurrence and impact of experienced workplace incivility. J. Occup. Health Psychol. 2015, 20, 205-217. [CrossRef]

64. Moon, C.; Sánchez-Rodríguez, Á. Cultural influences on normative reactions to incivility: Comparing individuals from South Korea and Spain. Int. J. Confl. Manag. 2020. [CrossRef] 